\title{
FEATURE Social impacts of citizen science water monitoring programs
}

\author{
Nancy Grudens-Schuck and Zulham Sirajuddin
}

$\mathrm{T}$ he drive to protect and improve surface water quality requires an array of policies, institutions, professionals, and procedures, even in the face of uncertain budgets and an increasing scope of work. Since the 1990s, the concept of "citizen science" has provided a framework under which volunteers supplement the water monitoring duties of scientists by producing more data and, in some cases, expanding their reach (Conrad and Hinchey 2011; McKinley et al. 2017). Volunteers, on the whole, benefit by contributing to society (Lawrence 2006), and by learning about science and environmental issues (Hecker et al. 2018; McKinley et al. 2017; Phillips et al. 2018). Many citizen science programs welcome youth, but this paper focuses on programs for adults.

Citizen science programs address many types of science, not just water monitoring. Species monitoring contributes to biodiversity conservation (e.g., bird counts, whale watching, and butterfly migration), and space science and astronomy programs have expanded (Dickinson et al. 2012). Water quality monitoring is considered to be one of the largest activities (Conrad and Hinchey 2011), with program numbers in the United States estimated from 1,675 (Stepenuck 2013) to 1,720 (National Water Quality Monitoring Council 2019). Volunteer water monitoring has provided scientists with more data, and from more locations, than originally hoped (Conrad and Hinchey 2011). Data produced by citizen science projects have contributed to science knowledge and to policy development on local, state, regional, and national levels (Dickinson et al. 2012; Lubell et al. 2002; McKinley et al. 2017).

Nancy Grudens-Schuck is an associate professor in the Department of Agricultural Education and Studies at lowa State University, Ames, lowa. Zulham Sirajuddin is a doctoral candidate in agricultural education at lowa State University and a lecturer at Universitas Ichsan Gorontalo, Indonesia.
Social impacts fall into two camps: learning and engagement (Dean et al.2018; Lewandowski and Oberhauser 2016). Both dimensions have been addressed unevenly on the programming level, and there are few studies that focus on outcomes. McGreavy et al. (2016) applied the term "nascent" to describe social and policy instruction of most citizen science programs. A meta-review by Stepenuck and Green (2015) of 436 peer-reviewed journal articles on citizen science reported that only $10 \%$ of articles adequately addressed social impacts of any type.

For water monitoring programs, learning outcomes are overwhelmingly represented by knowledge and skills required to complete specific water testing protocols (Lewandowski and Specht 2015; Stepenuck and Green 2015). The warrant for assessment of volunteers in this regard is to establish credibility of the data. Early on, critics of citizen science raised the specter of "bad data" collected by volunteers who typically are untrained in the subject area; volunteers are not required to be professional scientists or technicians in the content area, and most are not. Almost all programs train volunteers using site-specific protocols and equipment, but early in the citizen science era, it was not known if the training sufficed. Programs were eager for volunteer-collected data to be considered trustworthy in community disputes, governance and policy settings, and/or peer reviewed journal articles (Dickinson et al. 2012; Lewandowski and Specht 2015; Turrini et al. 2018). Studies such as those conducted by Fore et al. (2001); Muenich et al. (2016); and Storey et al. (2016) assessed adult volunteers' knowledge and skills related to stream water quality monitoring using different methods, such as comparison groups and one-to-one checks of samples by experts. Across studies, these reports showed that volunteers performed "well enough" or "almost as good" as the standard, which was received with satisfaction by each of the programs. Lewandowski and Specht (2015) surveyed the literature to show that volunteers sometimes exceeded experts in performance. Freitag et al. (2016) devised a list of 12 strategies to bolster data quality in citizen science programs, based on a study of 30 programs. Cronin and Messemer (2013) examined broader science learning by administering a 128-item self-report, pre-post Likert-type test to water monitors to measure science process knowledge (i.e., how to conduct science) in addition to domain-specific knowledge and skills (i.e., water monitoring) to show that statistically significant learning occurred in both broad and narrow knowledge arenas.

Engagement is the other social impact of citizen science, and it is even less frequently taught or assessed. Turrini et al. (2018) describe social engagement impacts of citizen science as "civic engagement and participation in environmental protection and conservation." Examples of engagement include (a) leadership of conservation organizations, and the ability of volunteers to affect the progress of legislation (McGreavy et al. 2016; Morton and Brown 2011); (b) volunteers who advocate for sustainability, ecosystem health, and environmental policies (Dean et al. 2018; Lubell et al. 2002; McKinley et al. 2017); (c) volunteers who successfully network and are able to productively engage in conflict resolution (Fernandez-Gimenez et al. 2008); and (d) volunteers who are motivated to tell others what they learned, and join conservation groups (Dean et al. 2018; Lewandowski and Oberhauser 2016; Stepenuck and Green 2015).

Social engagement was the focus of the program evaluation we conducted in 2016 of a citizen science water monitoring program, Iowater.

\section{BACKGROUND: IOWATER}

This article reports on an investigation of social engagement impacts of Iowater Volunteer Water Quality Monitoring Program, a citizen science water monitoring program. Iowater was a statewide program administered by the Iowa Department of Natural Resources (IDNR) for more than 20 years, which aimed to (a) involve the 
public in protecting water quality in Iowa, and (b) support watershed protection activities through water testing (IDNR 2002; Iowater Program 2010). The program was modified in 2016 and 2017 to a locally led format and renamed Volunteer Water Monitoring (IDNR 2017). Our program evaluation survey provided data for Iowater for up until 2016.

Iowater volunteer monitors (estimated 5,000 individuals over 20 years; 1,000 active estimated annually) generated data for local, as well as statewide, water quality assessments, baseline studies, and compliance reports. Iowater data have been used to substantiate Iowa's 305(b) Impaired Waters Report (Iowater 2010), required as part of the Clean Water Act, US Environmental Protection Agency (IDNR 2000; Iowater 2010; Riessen 2009). Iowa's water quality challenges include nonpoint source pollution, such as nutrients and sediment from row crop and livestock farming practices (IDALS et al. 2017; Riessen 2009). Data from Iowater have been used to promote voluntary adoption of farmland conservation practices, including management of water from urban and suburban settings (Iowater Program 2010). The formation of Iowater was closely associated with the development of watershed organizations (Morton and Brown 2011); 1999 watershed protection legislation (Riessen 2009); and approval for Water Management Authorities (IDALS et al. 2017).

\section{MEASUREMENT}

We measured social impacts of Iowater by surveying all registered volunteers (census survey) in 2016 as part of routine program evaluation activities that Iowater conducted periodically (IDNR 2002; Iowater Program 2010). Iowater's water monitoring training course administered its own satisfaction-oriented evaluation. In addition to social impact measures, the survey asked about database entry, benthic organism training, and other outcomes, which we have not reported here.

The study was delimited in the following ways. As a program evaluation, the findings are transferrable and are a source of learning for similar programs. However, the findings are not generalizable to a larger population in the same manner that findings generated from a study with a sample might be. There are also preferences among social scientists for quasi-experimental designs that use comparison or control groups to sharpen findings, but circumstances did not allow this feature. The study nonetheless employed high quality techniques for creating and administering scaled selfreport questions for a census survey, such as use of retrospective self-report formats. These findings may therefore be considered, in the vernacular, as standing in the middle ground between reflections on a program (our study contributed more than this) and a research investigation of effects of program structures (we were not set up for that). Moreover, our study was not intended to measure subject matter knowledge (water quality or water monitoring protocols), nor was it designed to provide a comprehensive portrait of the Iowater program.

\section{EVALUATION SURVEY}

Iowater's key issues for social engagement (Iowater Program 2010) formed the basis for our questions:

- Assist new partnerships and alliances

- Facilitate communication among volunteer groups, local landowners, and government agencies, to promote sharing of data and resources

- Provide a framework of information for citizen groups to use in actively promoting responsible decision making in protecting local water quality

The survey used a descriptive statistical design. We used retrospective self-report questions (Lam and Bengo 2003) because it was a good choice for the types of questions we wanted to ask (Nimon et al. 2011), and the program context did not permit a quasi-experimental design or a pre-post design.

Survey questions assessed included the following:

- Volunteer demographics, including confidence

- Engagement behaviors (informationseeking, networking, participation, and leadership)

- Iowater activities associated with engagement outcomes
The program provided a list of 2,165 active Iowater volunteers. We removed nonworking and duplicate entries to arrive at 1,782. We sent a Qualtrics online survey, approved by human subjects, four times to the mailing list. We received 611 responses. We removed partial and blank surveys, which resulted in a response rate of 31\%. T-tests were conducted with SPSS ver. 20 with the level of significance set at 0.01 .

\section{FINDINGS: VOLUNTEERS}

The study showed even distribution across the following age categories: 31 to 45 (24\%), 46 to $56(22 \%)$, and 57 to 65 (23\%). The category of ages 18 to 30 was lower, at $13 \%$. Seniors ages 65 to $75(15 \%)$ and older than $75(5 \%)$ volunteered at lower rates.

Over $90 \%$ of respondents indicated that they were certified by Iowater. Certification was not a legal status and had no renewal conditions, however equipment and communications were provided on this basis. "Four to eight years certified" was 30\% and "more than eight years certified" was 35\% and comprised the experienced monitor base of $65 \%$. Twenty-six percent indicated that their certification was "three years or less," which spoke to newcomers in the program. Nine percent were "not sure." Forty-one percent indicated that they had last participated in 2015 (the prior year); and 11\% in 2014; and the percentage points dropped off in increments of 10 until "earlier than 2000."

Global confidence in volunteers' ability to monitor water was measured using a three-part self-efficacy question (Bandura 1977) designed based on the following tenets: Do I have the knowledge? Can I perform in this domain? Do I have a place to perform these skills? Volunteers reported a high level of confidence in their global knowledge and skills required for water monitoring for Iowater (table 1).

FINDINGS: ENGAGEMENT BEHAVIORS Engagement was defined for the Iowater context as information-seeking, networking, participating, and showing leadership behaviors in the organizational and public water quality community.

Information Seeking. Two items indicated a positive change in information 
seeking behaviors (figure 1). Both questions were measured using retrospective self-report pairs (How would you rate yourself before participating in Iowater? What rating would you rate yourself now?). First, Iowater monitors reported a positive change in their ability to read and understand technical water quality reports, a precursor to policy involvement, as a result of participation in Iowater. A second question asked about enthusiasm for comparison of water quality data on the Iowater map website, which would include one's own data, but also that of other volunteers, across years.

Networking. Three retrospective selfreport questions measured changes in networking with water quality contacts, family, and colleagues (figure 2). The means for each variable indicate the differences between before and now. T-tests showed significant differences at the 0.001 level. The $p$-values for "talk to family and friends," "talk to colleagues," and "network with members of other water quality groups" comparisons are $p=0.0005, p=0.0000$, and $p=0.0005$.

Participation. Participation was defined as joining activities, becoming a new member or attending a conservation or water-related organization event, or joining a clean-up day. The question allowed multiple selections, and specified that the activity was something that "Iowater helped you to do" (an attributed outcome). "Participate in a watershed group" was the largest (53\%), then "clean-up day" (49\%), "join any other conservation group" (30\%), and "paddling or river group" (18\%) (table 2).

Leadership. Leadership was defined as drawing others into activities, as an "organizer." This category asked if there were leadership activities that "Iowater helped you to do." Multiple responses were permitted, and findings included "organizing clean-up days" (16\%), "organizing watershed groups" (15\%), and "organizing watershed authorities" (6\%).

\section{ACTIVITIES}

We asked questions about social contact during Iowater activities. This question was important to us because water monitoring is typically a solo venture, or

\section{Table 1}

Volunteer self-ratings for water monitoring knowledge and skills using a fourpoint self-efficacy scale.

\begin{tabular}{lc}
\hline Element & Mean \\
\hline I have the necessary knowledge and skills to perform lowater tasks. & 3.54 \\
I am confident I can apply my knowledge and skill in lowa and have good results. & 3.56 \\
I have somewhere to practice the knowledge and skills that are key to lowater. & 3.49
\end{tabular}

\section{Figure 1}

Volunteers' knowledge and skill related to water quality policy before and after lowater.

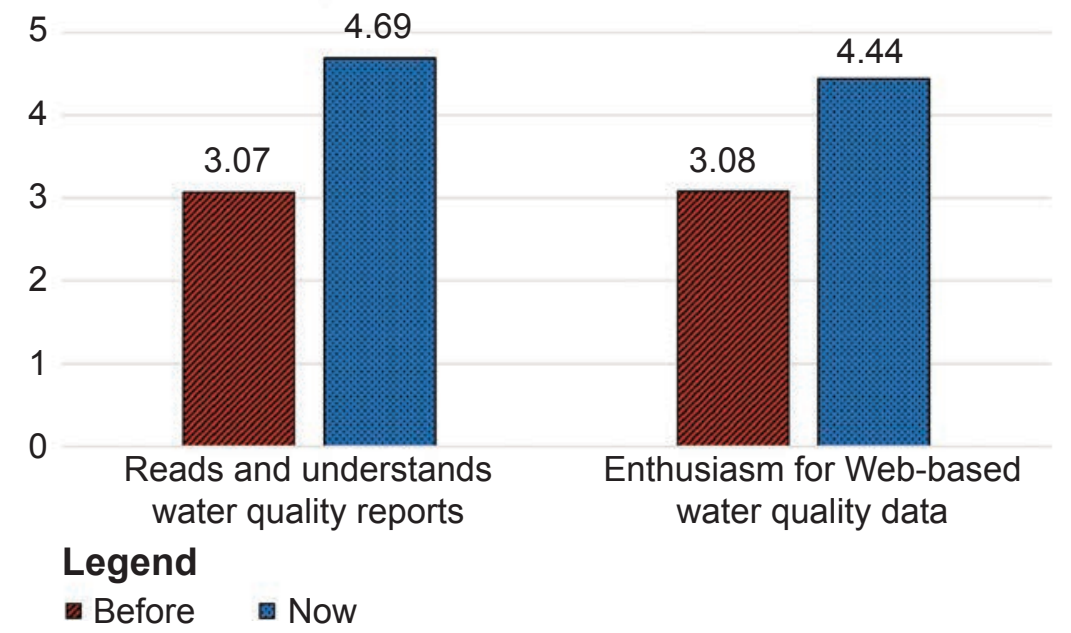

\section{Figure 2}

Comparing ease of networking before and after lowater. Behaviors were rated on sixpoint scales. Data are presented as means.

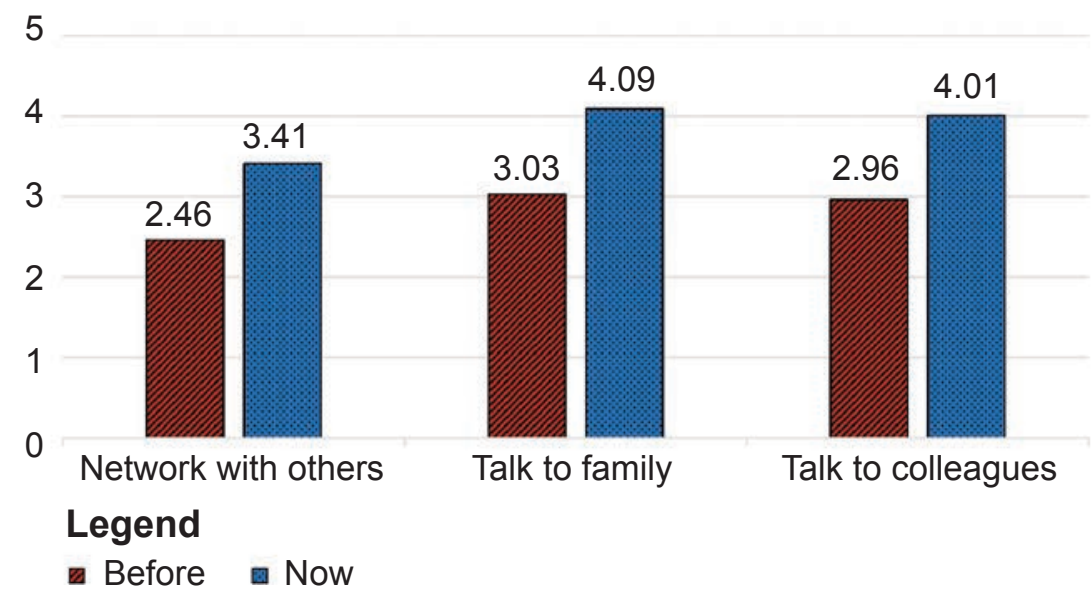


involved one other family member or close contact individual, from whom learning was expected to be more limited than from new contacts. The survey gathered information about the most visible single activity associated with group monitoring, the Snapshot. The Snapshot was designed to be a data quality check. On the day of a Snapshot, monitors across the state sampled water, and this occurred typically once in spring and once in fall. We knew from informal knowledge about the Snapshots that they were occasions associated with greater social interaction.

Before, on, and after the day of the Snapshot (table 2), 59\% reported that "someone locally organizes us," $25 \%$ said "a team meets face to face," and $27 \%$ reported "some of us may visit the test sites together." Fifteen percent responded that they tested alone during the Snapshot. For "on or after a Snapshot," the highest responses listed "comparison of water quality data" (52\%),"sharing how sites have changed physically" (37\%), and "problems with equipment" (36\%), but $28 \%$ and $25 \%$ indicated "discussions regarding upcoming events related water quality meetings" and "discussions regarding strategies for water quality initiatives." Multiple selections were permitted.

It is important to state, and greatly limiting to the findings regarding these activities, that $77 \%$ of respondents indicated that they never participated in a Snapshot.

\section{DISCUSSION}

Respondents who participated in the Iowater social impacts survey were experienced and confidant water monitoring volunteers. The response rate was lower than desired, but adequate. Iowater delivered social impacts in key areas related to program goals, particularly with respect to support of watershed organizations. Volunteers reported positive changes in several areas, and no negative results. Policy inclinations, through understanding and enjoying technical water quality reports and water quality data on web-based maps, reported gains. Volunteers reported gains in three areas of networking: with members of other water quality groups, with family and friends, and with colleagues. In presentations of these results with cli-

\section{Table 2}

Activities before, on, or after a Snapshot. This question allowed multiple responses.

\begin{tabular}{ll}
\hline Statement & Response (\%) \\
\hline Someone locally organizes us by email, phone, or text. & 59 \\
A team meets face to face. & 25 \\
Some of us may visit the test sites together. & 27 \\
Currently I test without a team, but may bring someone with me to the site. & 25 \\
Currently I test without a team, and I don't bring anyone with me to the site. & 15 \\
We compare test site water quality data. & 52 \\
We share how sites have changed physically. & 37 \\
We share how sites may be more or less dangerous (banks, water flow). & 29 \\
We tell about upcoming meetings related to water quality. & 28 \\
We discuss strategies for upcoming or ongoing water quality initiatives. & 25 \\
We share problems with equipment or collection & 36 \\
We set deadlines for completing activities, especially uploading data. & 11
\end{tabular}

ents and at water-related conferences, networking was deemed a challenging interpersonal skill, and its development was highly valued.

Outcomes specific to the Iowater mission included participation in a watershed group, and participation in a clean-up day, and half of volunteers attributed at least part of their participation to Iowater. The leadership-oriented set of "organizing" outcomes scored low $(16 \%, 15 \%$, and $6 \%$ ), but were comprised of actions that required sophisticated behaviors and, in one case, a new legal entity (Watershed Management Authorities) and would be expected to be lower. To see some outcomes in this category attributed to participation in Iowater was received positively by program officials.

Together, the several outcomes affirm a clear, if emerging skill set, with appropriate pro-social emotional anchors, which may support watershed and environmental initiatives and organizations in a continuum from active member to activist. Moreover, the set is amenable to evaluation and assessment by survey and the many other qualitative and quantitative approaches.

\section{KEY OBSERVATIONS}

We distilled our findings into the following three observations:

1.A mature, statewide citizen science water monitoring program, populated with experienced and confident monitors, delivered social impacts for volunteers.
It is likely that other similar water monitoring programs can do the same.

2. Iowater volunteers made gains in communications and interpersonal areas such as networking and joining conservation activities, and developing readiness for policy work.

3. Iowater assisted a much smaller number of volunteers to provide leadership for organizing watershed-type organizations.

\section{CONUNDRUMS AND FUTURE STUDY}

The evaluation did not establish how Iowater provided outcomes. Specifically, there were no easily identifiable activities associated with the strong gains identified in the survey.

1. Like many outcomes-oriented studies, we did not discern a mechanism for the source of change. More troubling, we lacked clear candidates. What feature in the program caused the change? Similar to many water monitoring programs, Iowater did not offer direct instruction on social engagement (workshops, webinars, speakers, conferences, mentors).

2. The single instance of teamwork, the Snapshot, provided preliminary data for evidence that social learning contributed to social impact gains in a peer-to-peer style. However, almost all volunteers never attended a Snapshot. This is a promising line for future study, but it does not settle our question of mechanism at this time. 
3. Yet neither did we have evidence to say that "just monitoring water" produced social impacts. A few studies have shown that surprise and disgust- such as experiencing water pollution-can lead to the urge to commit to environmentalism (Dean et al. 2018), but emotion must usually be combined with social skills. For now, we do not endorse the idea of water monitoring as the core activity on which social engagement outcomes were based.

4. Conducting research on social impacts from citizen science programs is a promising endeavor. It need not be expensive. We completed this study with readily available, low-cost survey technology and commonly accepted (if less used, in the case of retrospective self-reports) techniques, which enabled us to measure social impacts. Internal evaluators, Extension evaluators, nonprofit or government agency staff, or combinations of faculty and graduate students could make solid contributions.

\section{CONCLUSION}

Iowater was a mature program when we evaluated volunteer citizen scientists, called water monitors, for social engagement impacts. Most water monitoring programs do not routinely assess for social impacts, either knowledge or engagement. The most frequent type of assessment of volunteers is to check for competence related to water testing to ensure high quality data.

The Iowater experience shows that a range of social engagement outcomes can be realized for a citizen science water monitoring program. We are aware that some programs do not seek to develop social engagement skills of volunteers, but others do. Evaluating outcomes is not onerous.

Our study could not point to a set of activities that generated the outcomes for Iowater volunteers. Iowater, like most citizen science programs, did not offer workshops or webinars related specifically to social engagement. We speculate that peer-to-peer learning played an important role, instead. Peer learning is understood in the psychology and education literature as social learning, a framework established by Bandura (1977), and is successfully applied in many contexts. Iowater offered the biannual Snapshot, which functioned as peer learning, but not enough respondents participated to allow us to arrive at a conclusion we trusted.

However, we are comfortable speculating that a water monitoring program might be successful in increasing social impacts among greater numbers of its volunteers by encouraging and organizing regular events for volunteers to share, plan, and collect data together, such as the statewide Snapshot, or in other formats locally or regionally. Social learning may occur during interactive workshops, conferences, or retreats, but it also may occur during travel to events, in parking lots while comparing samples, or on river bank walks. The salient points for social learning are modeling and mastery, among individuals. Determination of a right-sized educational format benefits from creativity and by keeping the design close to the context that your volunteers value.

\section{ACKNOWLEDGEMENTS}

Mary Skopec, former director of the Iowater Volunteer Water Quality Program and Beach Monitoring, Iowa Department of Natural Resources (IDNR), was generous with her time and provided access to Iowater program materials. Steven Konrady, IDNR, assisted with usage of the evaluation findings. Janice Larson and Zhulin He, Survey Research Services Unit, Iowa State University Statistical Laboratory, provided guidance on survey questions and statistical analysis. An earlier version of the paper was presented at the 2017 Iowa Water Conference in Ames, Iowa. This article is a product of the Iowa Agriculture and Home Economics Experiment Station, Ames, Iowa; project No. IOW05511 is sponsored by Federal Hatch Act and State of Iowa funds.

\section{REFERENCES}

Bandura,A. 1977. Social Learning Theory. Englewood Cliffs, NJ: Prentice Hall.

Conrad, C.C., and K.G. Hinchey. 2011. A review of citizen science and community-based environmental monitoring: Issues and opportunities. Journal of Environmental Monitoring and Assessment 176:273-291. http://dx.doi:10.1007/ s10661-010-1582-5.

Cronin, D.P., and J.E. Messemer. 2013. Elevating adult civic science literacy through a renewed citizen science paradigm. Adult Learning 24(4):143-150.
Dean, A.J., E.K. Church, J. Loder, K.S. Fielding, and K.S. Wilson. 2018. How do marine and coastal citizen science experiences foster environmental engagement? Journal of Environmental Management 213:409-416. https://doi. org/10.1016/j.jenvman.2018.02.080.

Dickinson, J.L., J. Shirk, D. Bonter, R. Bonney, R.L. Cain, J. Martin, T. Phillips, and K. Purcell. 2012. The current state of citizen science as a tool for ecological research and public engagement. Frontiers in Ecology and the Environment 10(6):291-297. https://doi.org/10.1890/110236.

Fernandez-Gimenez, M.E., H.L. Ballard, and V.E. Sturtevant.2008.Adaptive management and social learning in collaborative and community-based monitoring: A study of five community-based forestry organizations in the western USA. Ecology and Society 13(2). http://www.ecologyandsociety.org/vol13/iss2/art4/.

Fore, L.S., K. Paulsen, and K. O'Laughlin. 2001. Assessing the performance of volunteers in monitoring streams. Freshwater Biology 46(1):109-123, doi:10.1111/j.1365-2427.2001.00640.x.

Freitag, A., R. Meyer, and L.Whiteman. 2016. Strategies employed by citizen science programs to increase the credibility of their data. Citizen Science: Theory and Practice 1(1). http://doi. org/10.5334/cstp.6.

Hecker, S., M. Hacklay, A. Bowser, Z. Makuch, J. Vogel, and A. Bonn. 2018. Citizen Science: Innovation in Open Science, Society and Policy. London: University College London Press.

IDALS (Iowa Department of Agriculture and Land Stewardship), IDNR (Iowa Department of Natural Resources), and Iowa State University College of Agriculture and Life Sciences. 2017. Iowa Nutrient Reduction Strategy: Annual Progress Report: 2016-2017 INRS \#0015. Des Moines, IA: Iowa Department of Agriculture and Land Stewardship.

IDNR (Iowa Department of Natural Resources). 2000. Iowa's Water Monitoring Plan. Des Moines, IA: Iowa Department of Natural Resources.

IDNR. 2002. Iowater Executive Summary 20002003. Des Moines, IA: Iowa Department of Natural Resources.

IDNR. 2017. Iowa Watershed Improvement Program: Locally-led Water Monitoring. Des Moines, IA: Iowa Department of Natural Resources, Environmental Services Division.

Iowater Program. 2010. Quality Assurance Project Plan for Iowater. QA/WM/01-02. Iowa City, IA: IDNR, Watershed Monitoring and Assessment Program, Iowater. 
Lam, T.C.M., and P. Bengo. 2003. A comparison of three retrospective self-reporting methods of measuring change in instructional practice. American Journal of Evaluation 24(1):65-80, doi:10.1016/S1098-2140(02)00273-4.

Lewandowski, E.J., and K.S. Oberhauser. 2016. Butterfly citizen science projects support conservation activities among their volunteers. Citizen Science: Theory and Practice 1(1). http://doi. org/10.5334/cstp.10.

Lewandowski, E., and H. Specht. 2015. Influence of volunteer and project characteristics on data quality of biological surveys. Conservation Biology 29(3):713-723, doi:10.1111/cobi.12481.

Lawrence, A. 2006. 'No personal motive?' Volunteers, biodiversity, and the false dichotomies of participation. Ethics, Place, and Environment 9(3): 279-298. https://doi. org/10.1080/13668790600893319.

Lubell, M., M. Schneider, J.T. Scholz, and M. Mete. 2002. Watershed partnerships and the emergence of collection action institutions. American Journal of Political Science 46(1):148-163. http://www. jstor.org/stable/3088419.

McGreavy, B., A.J.K. Calhoun, J. Jansujwicz, and V. Levesque. 2016. Citizen science and natural resource governance: Program design for vernal pool policy innovation. Ecology and Society 21(2). http://dx.doi.org/10.5751/ ES-08437-210248.

McKinley, D.C., A.J. Miller-Rushing, H.L. Ballard, R. Bonney, H. Brown, S. Cook-Patton, D.M. Evans, et al. 2017. Citizen science can improve conservation science, natural resource management, and environmental protection. Biological Conservation 208:15-28. http://dx.doi. org/10.1016/j.biocon.2016.05.015.

Morton, L.W., and S.S. Brown, eds. 2011. Pathways for Getting to Better Water Quality: The Citizen Effect. New York: Springer.

Muenich, R.L., S. Peel, L.C. Bowling, M.H. Heller, R.F. Turco, J.R. Frankenberger, and I. Chaubey. 2016. The Wabash Sampling Blitz: A study on the effectiveness of citizen science. Citizen Science: Theory and Practice 1(1). http://doi. org/10.5334/cstp.1.

National Water Quality Monitoring Council. 2019. Volunteer Monitoring. https://acwi.gov/monitoring/vm/index.html.

Nimon, K., D. Zigarmi, and J. Allen. 2011. Measures of program effectiveness based on retrospective pretest data: Are all created equal? American Journal of Evaluation 32(1):8-28, doi:10.1177/1098214010378354.

Phillips, T., N. Porticella, M. Constas, and R. Bonney. 2018. A framework for articulating and measuring individual learning outcomes from participation in citizen science. Citizen Science: Theory and Practice 3(2):1-19. http://doi.org/10.5334/ cstp.126.

Riessen, J. 2009. Comprehensive Water Planning in Iowa: Past Efforts. Des Moines, IA: Iowa Department of Natural Resources.

Stepenuck, K.F. 2013. Improving understanding of outcomes and credibility of volunteer environmental monitoring programs. $\mathrm{PhD}$ dissertation, University of Wisconsin-Madison.

Stepenuck, K.F., and L.T. Green. 2015. Individual- and community-level impacts of volunteer environmental monitoring: A synthesis of peer-reviewed literature. Ecology and Society 20(3):1-16. http://dx.doi.org/10.5751/ES-07329-200319.

Storey, R.G., A. Wright-Stow, E. Kin, R. DaviesColley, and R. Stott. 2016. Volunteer stream monitoring: Do the data quality and monitoring experience support increased community involvement in freshwater decision making? Ecology and Society 21(4):32. https:// doi.org/10.5751/ES-08934-210432.

Turrini,T,, D. Dörler,A. Richter, F. Heigl, and A. Bonn. 2018. The threefold potential of environmental citizen science: Generating knowledge, creating learning opportunities and enabling civic participation. Biological Conservation 225:176-186. https://doi.org/10.1016/j.biocon.2018.03.024. 